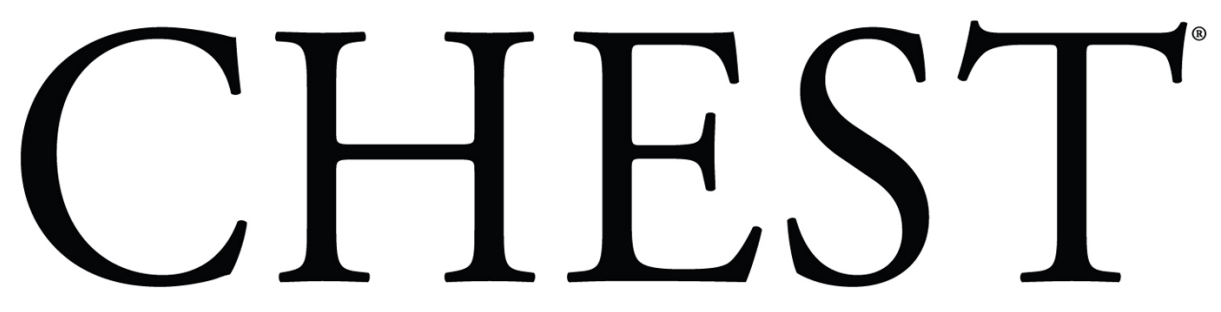

Official publication of the American C ollege of Chest Physicians

\title{
Is Tracheal Stenosis Caused by Percutaneous Tracheostomy Different From That by Surgical Tracheostomy?
}

Govindan Raghuraman, Sunil Rajan, Joseph Khalil Marzouk, Dam Mullhi and Fang G. Smith

Chest 2005;127;879-885

DOI 10.1378/chest.127.3.879

The online version of this article, along with updated information and services can be found online on the World Wide Web at: http://chestjournals.org/cgi/content/abstract/127/3/879

CHEST is the official journal of the American College of Chest

Physicians. It has been published monthly since 1935. Copyright 2007 by the American College of Chest Physicians, 3300 Dundee Road, Northbrook IL 60062. All rights reserved. No part of this article or PDF may be reproduced or distributed without the prior written permission of the copyright holder

(http://www.chestjournal.org/misc/reprints.shtml). ISSN: 0012-3692.

\section{A M E R I C A N C O L L E G E O F}

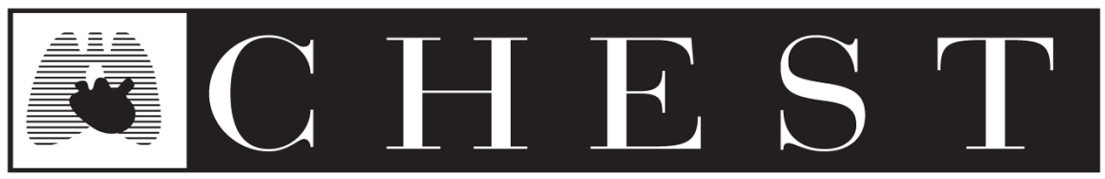
$\mathrm{P} \quad \mathrm{H}$
Y
$\mathrm{S} \quad \mathrm{I}$
C
I
A $\quad \mathrm{N} \quad \mathrm{S}^{\circledR}$ 


\title{
Is Tracheal Stenosis Caused by Percutaneous Tracheostomy Different From That by Surgical Tracheostomy?*
}

\author{
Govindan Raghuraman, MBBS; Sunil Rajan, MBBS; \\ Joseph Khalil Marzouk, MBBS; Dam Mullhi, MBBS; and \\ Fang G. Smith, MBBS, MPhil
}

\begin{abstract}
Study objective: To compare the surgical findings of tracheal stenosis caused by percutaneous tracheostomy (PCT) and surgical tracheostomy (SGT).

Design and setting: A combined prospective (from 2001 to 2003) and retrospective (from 1993 to 2001) observational study of the patients undergoing tracheal resection and reconstruction for treatment of tracheal stenosis following PCT or SGT in a national referral center for thoracic surgery in the United Kingdom.

Patients and measurements: We studied 29 patients presenting with symptomatic tracheal stenosis requiring tracheal reconstruction. We recorded the demographic data, duration of mechanical ventilation, onset of tracheal stenosis after decannulation, and type of tracheostomy (PCT or SGT) from referral notes. Tracheal reconstruction was preceded by rigid bronchoscopy, through which the distance of the superior level of stenosis to the vocal cords, and the length and the diameter of stenosis were measured. The type of surgical technique for tracheal resection was also recorded. We then compared the stenosis caused by PCT $(n=15)$ and SGT $(n=14)$ using an unpaired $\boldsymbol{t}$ test, Mann-Whitney $U$ test, or Fisher exact test as appropriate for statistical analysis. Results: The mean distance from the superior level of stenosis in the PCT group was significantly closer to the vocal cords compared with the mean distance in the SGT group: $1.6 \mathrm{~cm}(95 \%$ confidence interval $[\mathrm{CI}], 1.1$ to 2.1$)$ vs $3.4 \mathrm{~cm}(95 \% \mathrm{CI}, 2.3$ to 4.5$)$, respectively $(p=0.04)$. The mean onset of stenosis was significantly earlier in the PCT group compared to the SGT group: 5.0 weeks (95\% CI, 5.0 to 6.0$)$ vs 28.5 weeks $(95 \%$ CI, 12 to 84$)$, respectively $(p=0.009)$. Seven of 15 patients in the PCT group required partial cricoid resection and a mucosal flap, compared with 1 of 14 patients in the SGT group, although the difference did not reach statistic significance $(\mathbf{p}=\mathbf{0 . 2 3})$.

Conclusion: Stenosis caused by PCT occurred earlier and was subglottic in nature compared to that by SGT. Surgical correction of stenosis was more difficult in the PCT group due to its presentation in the subglottic area.

(CHEST 2005; 127:879-885)
\end{abstract}

Key words: percutaneous tracheostomy; subglottic stenosis; surgical tracheostomy

Abbreviations: CI = confidence interval; PCT = percutaneous tracheostomy; SGT = surgical tracheostomy

$\mathbf{T}$ he average internal diameter of an adult trachea is $2.5 \mathrm{~cm}$, and the subglottic space that is defined as the area $5 \mathrm{~mm}$ below the vocal cords to the under surface of the cricoid cartilage has an average internal diameter of $1.7 \mathrm{~cm}$. Tracheal stenosis following tracheostomy can occur at microscopic and macroscopic levels. Microscopic stenosis occurs in almost

${ }^{\star}$ From Anaesthesia and Intensive Care Medicine (Drs. Raghuraman, Smith, and Mullhi), Thoracic Surgery (Dr. Marzouk), and Cardiothoracic Surgery (Dr. Rajan), Departments of Anaesthesia and Thoracic Surgery, Birmingham Heartlands Hospital, Birmingham Heartlands and Solihull NHS Trust (Teaching), Bordesley Green East, Birmingham, UK.

Manuscript received December 16, 2003; revision accepted September 3, 2004. all cases. However, clinically significant macroscopic stenosis occurs when the diameter of the trachea is reduced by $>50 \%$ of its original diameter. ${ }^{1,2}$ Clinical tracheal stenosis, as the most serious long-term complication following tracheostomy, ${ }^{3}$ can be life threatening. The most effective treatment is tracheal resection and primary end-to-end reconstruction. However, stenosis in the subglottic area usually

\footnotetext{
Reproduction of this article is prohibited without written permission from the American College of Chest Physicians (e-mail: permissions@chestnet.org).

Correspondence to: Fang G. Smith, MBBS, Birmingham Heartlands Hospital, Birmingham Heartlands and Solihull NHS Trust (Teaching), Bordesley Green East, Birmingham, B9 5SS, UK; e-mail:f.g.smith@bham.ac.uk
} 
makes resection much more difficult and requires high surgical skills. Otherwise, the patient may require intermittent dilatation for life or a permanent tracheostomy. It is therefore essential to use a most reliable method to diagnosis the location and the severity of stenosis in order to select the most appropriate treatment and to minimize the worst long-term outcomes in this devastating complication.

Several studies ${ }^{4}$ have challenged the sensitivity of noninvasive investigations, such as flow-volume loops, spiral CT, and MRI, in assessing the location and severity of a stenosis. Clinical symptoms and examination are not sensitive in diagnosing tracheal stenosis. ${ }^{1,5}$ Pulmonary function tests are diagnostic only if the diameter of the trachea is reduced by $50 \% .^{1,4}$ Routine radiographs of the trachea are not helpful in these cases. ${ }^{6}$ Although fiberoptic bronchoscopy allows direct visualization of the proximal end of the stenosis, it is unlikely to be able to assess the diameter and the length of the stenosis because the diameter of the fiberoptic bronchoscope may exceed the diameter of the stenosis. A thoracic CT is useful, but the axial views make it difficult to visualize the contour and the extent of airway injury, and it provides little or no information over plain tomography.1,6,7 Although spiral CT and MRI are extremely helpful in identifying the location and the extent of stenosis, they are not helpful in assessing the mucosal abnormalities that may extend beyond the stenotic lesions that need to be excised for a curative surgical resection. Hence, surgical findings of a tracheal stenosis using a rigid bronchoscope and dilators are probably the most reliable in determining the location and severity of stenosis.

There have been no studies comparing the surgical findings of tracheal stenosis caused by percutaneous tracheostomy (PCT) with surgical tracheostomy (SGT). Our institution, as a national referral center for tracheal surgery, has patients referred for tracheal reconstruction for treatment of tracheal stenosis. Hence, this study was designed to compare surgical findings of tracheal stenosis caused by PCT with those by SGT.

\section{Materials AND Methods}

Having obtained the approval of local research ethics committee, we conducted a prospective (from 2001 to 2003) and retrospective (from 1993 to 2001) observational study. Patients who underwent tracheostomy (either PCT or SGT) for weaning from mechanical ventilation or for airway management with subsequent development of symptomatic tracheal stenosis, defined as dyspnoea on exertion and/or stridor (Table 1), were included in the study. Most of these patients had established diagnoses based on clinical presentation (dyspnea, stridor), CT scan or MRI scan, and/or fiberoptic bronchoscopy, which confirmed the presence of tracheal narrowing prior to referral. Age, gender, weight, duration of ventilation, and interval between decannulation and the development of symptoms were recorded from case notes review. We attempted but were unable to record the duration of endotracheal intubation prior to tracheostomy. Patients with two or more tracheostomies, with an unknown type of tracheostomy (PCT or SGT), or with known preexisting tracheal abnormalities prior to tracheostomy (such as tracheal tumor, congenital tracheal abnormality or tracheomalacia after thyroid goiter) were excluded from the study. Patients with more than one period of endotracheal intubation and mechanical ventilation were also excluded from this study.

A single operator (J.K.M.), using a rigid bronchoscope and dilators prior to surgery, obtained surgical findings. The internal diameter of the stenosis was measured with the largest size (in millimeters) of a tracheal dilator passing through the stenotic orifice prior to dilatation. Then the trachea was dilated up to a maximum possible level, and the rigid bronchoscope was passed beyond the stenotic segment up to the level of the carina. The bronchoscope was gradually withdrawn from the carina up to the vocal cords. During this process, the following measurements were made using black silk threads tied on the rigid bronchoscope at the level of the upper central incisors and quantified using a ruler in millimeters: (1) the distance between the carina to the lower level of the stenosis; (2) the length of the stenotic segment of the trachea; (3) the distance between the vocal cords and the upper level of stenosis; and (4) the total length of the trachea from the vocal cords to the carina. This is illustrated in Figure 1.

During the reconstructive procedure, which was usually a week after rigid bronchoscopic assessment, the operator also examined the shape of the tracheal stenosis, involvement of fractured tracheal rings, or of granulations at the level of stenosis, and distinguished stomal stenosis from nonstomal stenosis. The same operator (J.K.M.) performed all of the tracheal resections in this study. The types of surgical techniques were recorded from the operative record.

The data were tested for normality, and an unpaired $t$ test or Mann-Whitney $U$ test as appropriate were used for statistical analysis. The data were expressed as mean (SD), 95\% confidence intervals (CIs), or median (interquartile range); $\mathrm{p}<0.05$ was considered statistically significant.

\section{RESUlts}

During the study period, 32 patients underwent tracheal resections for the treatment of tracheal stenosis caused by tracheostomy. Three of these patients were found to have nonstomal stenosis $(\mathrm{n}=1$, around the vocal cords, following PCT; $\mathrm{n}=2$, around the cuff, one following PCT and another following SGT). Therefore, the data of 29 patients with stoma stenosis caused either by PCT or SGT were analyzed.

Among these 29 patients, 15 patients underwent PCT previously, and 14 patients underwent SGT previously. The general information and surgical findings of individual patients are shown in Table 1. As shown in Table 2, the general information was comparable between the two groups: there was no statistical significance between two groups in age, gender, weight, and duration of mechanical ventilation. However, the mean onset of stenosis was significantly shorter in the PCT group compared to 
Table 1-General Information and Surgical Findings of Individual Patients*

\begin{tabular}{|c|c|c|c|c|c|c|c|c|c|c|c|}
\hline Patients & $\begin{array}{l}\text { Age, } \\
\text { yr }\end{array}$ & Sex & $\begin{array}{l}\text { Weight, } \\
\text { kg }\end{array}$ & $\begin{array}{l}\text { MV, } \\
\text { d }\end{array}$ & $\begin{array}{l}\text { Onset, } \\
\text { wk }\end{array}$ & Symptoms & $\begin{array}{c}\text { Distance } \\
\text { Below } \\
\text { Vocal Cords, } \\
\text { cm }\end{array}$ & $\begin{array}{l}\text { Length, } \\
\text { cm }\end{array}$ & $\begin{array}{l}\text { Diameter, } \\
\text { mm }\end{array}$ & Other Findings & $\begin{array}{c}\text { Partial } \\
\text { Cricoid } \\
\text { Resection } \\
\text { and Flap }\end{array}$ \\
\hline \multicolumn{12}{|l|}{ PCT } \\
\hline 1 & 69 & Male & 80 & 17 & 4 & Dyspnea, stridor & 1 & 2.5 & 5 & Devoid of cartilage & Yes \\
\hline 2 & 49 & Female & 135 & 20 & 5 & Dyspnea, stridor & 3 & 1.8 & 5 & & \\
\hline 3 & 21 & Male & 82 & 14 & 8 & Dyspnea, stridor & 2.5 & 2.5 & 3 & & \\
\hline 4 & 30 & Female & 64 & 13 & 5 & Dyspnea, stridor & 2 & 2.8 & 2 & & \\
\hline 5 & 35 & Male & 76 & 22 & 7 & Dyspnea, wheeziness & 1.8 & 4 & 8 & & \\
\hline 6 & 38 & Female & 45 & 29 & 6 & $\begin{array}{l}\text { Dyspnea, stridor, } \\
\text { wheeziness }\end{array}$ & 0 & 4 & 6 & $\begin{array}{l}\text { Suprastoma devoid of } \\
\text { cartilage }\end{array}$ & Yes \\
\hline 7 & 22 & Male & 57 & 90 & 5 & Dyspnea, stridor & 2.5 & 3.5 & 1.5 & & \\
\hline 8 & 63 & Female & 68 & 12 & 6 & Dyspnea, stridor & 2 & 2.3 & 6 & Tracheoesophageal fistula & \\
\hline 9 & 28 & Male & 75 & 31 & 4 & Dyspnea, stridor & 2.5 & 2.5 & 8 & Suprastoma fractures & \\
\hline 10 & 53 & Female & 75 & 23 & 2 & Dyspnea, stridor & 0 & 3 & 5 & & Yes \\
\hline 11 & 53 & Female & 70 & 42 & 8 & Dyspnea, stridor & 1 & 2.5 & 1 & & Yes \\
\hline 12 & 35 & Male & 80 & 22 & 5 & Dyspnea, wheeziness & 1 & 3 & 8 & & Yes \\
\hline 13 & 24 & Male & 76 & 25 & 6 & Dyspnea, wheeziness & 1 & 4 & 7 & & Yes \\
\hline 14 & 48 & Male & 95 & 27 & 5 & Dyspnea, stridor & 2 & 1.5 & 2 & Suprastomal fractures & \\
\hline 15 & 67 & Female & 60 & 25 & 6 & Dyspnea, stridor & 1 & 2.5 & 4 & Tracheoesophageal fistula & Yes \\
\hline \multicolumn{12}{|l|}{ SGT } \\
\hline 1 & 20 & Male & 48 & 16 & 16 & Dyspnea, stridor & 6.5 & 2 & 3.5 & Infrastoma granulations & \\
\hline 2 & 58 & Male & 75 & 31 & 12 & Dyspnea, stridor & 3 & 4 & 4 & & \\
\hline 3 & 53 & Male & 76 & 12 & 30 & Dyspnea, stridor & 5.2 & 3 & 1.5 & & \\
\hline 4 & 27 & Female & 49 & 56 & 12 & Dyspnea, wheeziness & 2 & 2 & 6 & & \\
\hline 5 & 46 & Female & 73 & 25 & 24 & Dyspnea, stridor & 8 & 1.5 & 3 & $\begin{array}{l}\text { Tracheocutaneous fistula, } \\
\text { infrastoma granulations }\end{array}$ & \\
\hline 6 & 69 & Female & 94 & 2 & 4 & Dyspnea, stridor & 2.5 & 2 & 5 & Suprastoma granulations & \\
\hline 7 & 55 & Male & 75 & No data & 12 & Dyspnea & 1.5 & 3.5 & 6 & Suprastoma granulations & Yes \\
\hline 8 & 38 & Male & 101 & 18 & 84 & Dyspnea, stridor & 2.5 & 3.5 & 5 & & \\
\hline 9 & 55 & Female & 97 & No data & 84 & $\begin{array}{l}\text { Dyspnea, stridor, } \\
\text { wheeziness }\end{array}$ & 2 & 3 & 8 & & \\
\hline 10 & 47 & Male & 80 & 24 & 306 & $\begin{array}{l}\text { Dyspnea, stridor, } \\
\text { wheeziness }\end{array}$ & 2.3 & 2.2 & 4.5 & & \\
\hline 11 & 66 & Female & 65 & 45 & 30 & Dyspnea, stridor & 2.3 & 1.8 & 6 & & \\
\hline 12 & 60 & Female & 90 & 22 & 27 & Dyspnea, stridor & 3.5 & 3 & 4 & & \\
\hline 13 & 65 & Female & 75 & 12 & 52 & Dyspnea, stridor & 3.5 & 3.5 & 4 & & \\
\hline 14 & 24 & Female & 72 & 25 & 84 & Dyspnea & 2.5 & 2.2 & 6 & & \\
\hline
\end{tabular}

$* \mathrm{MV}=$ mechanical ventilation.

the SGT group: 5.0 weeks (95\% CI, 5.0 to 6.0 ) vs 28.5 weeks (95\% CI, 12 to 84), respectively $(\mathrm{p}=0.009)$. In the PCT group, the mean upper level of stenosis was significantly closer to the vocal cords compared to the surgical group: $1.6 \mathrm{~cm}$ (95\% CI, 1.1 to 2.1$)$ vs $3.4 \mathrm{~cm}(95 \% \mathrm{CI}, 2.3$ to 4.8$)$, respectively $(\mathrm{p}=0.04)$. Suprastomal cartilage damage (fracture or devoid) resulting in tracheal wall "caving-in" was a typical surgical finding in the PCT group (Fig 2), while marked (infra/supra) stomal granulations were frequently seen in the SGT group. The length of stenosis was similar between the two groups. Both groups were found to have a significant degree of stenosis (95\% CI, 3.4 to $6.2 \mathrm{~mm}$; 13.6 to $24.8 \%$ in diameter) compared with the average diameter of an adult trachea $(25 \mathrm{~mm}) .{ }^{8}$ In the PCT group, there were two cases of tracheoesophageal fistula, while there were none in the SGT group. A more compli- cated surgical technique (partial cricoid resection with mucosal flap) was more frequently used in PCT group ( 7 of 15 patients) $)^{8,9}$ than SGT ( 1 of 14 patients), although the difference did not reach statistical significance $(\mathrm{p}=0.23)$.

A postoperative follow-up with rigid bronchoscopy was carried out in all 29 patients annually for a consecutive 3 years. The tracheal resection surgery was successful in 28 of 29 cases. One patient required repeated dilatation once during the 3-year follow-up period.

\section{Discussion}

In this study, we found that the tracheal stenosis caused by PCT was significantly closer to the vocal cords compared to the SGT: $1.6 \mathrm{~cm}(95 \% \mathrm{CI}, 1.1$ to 


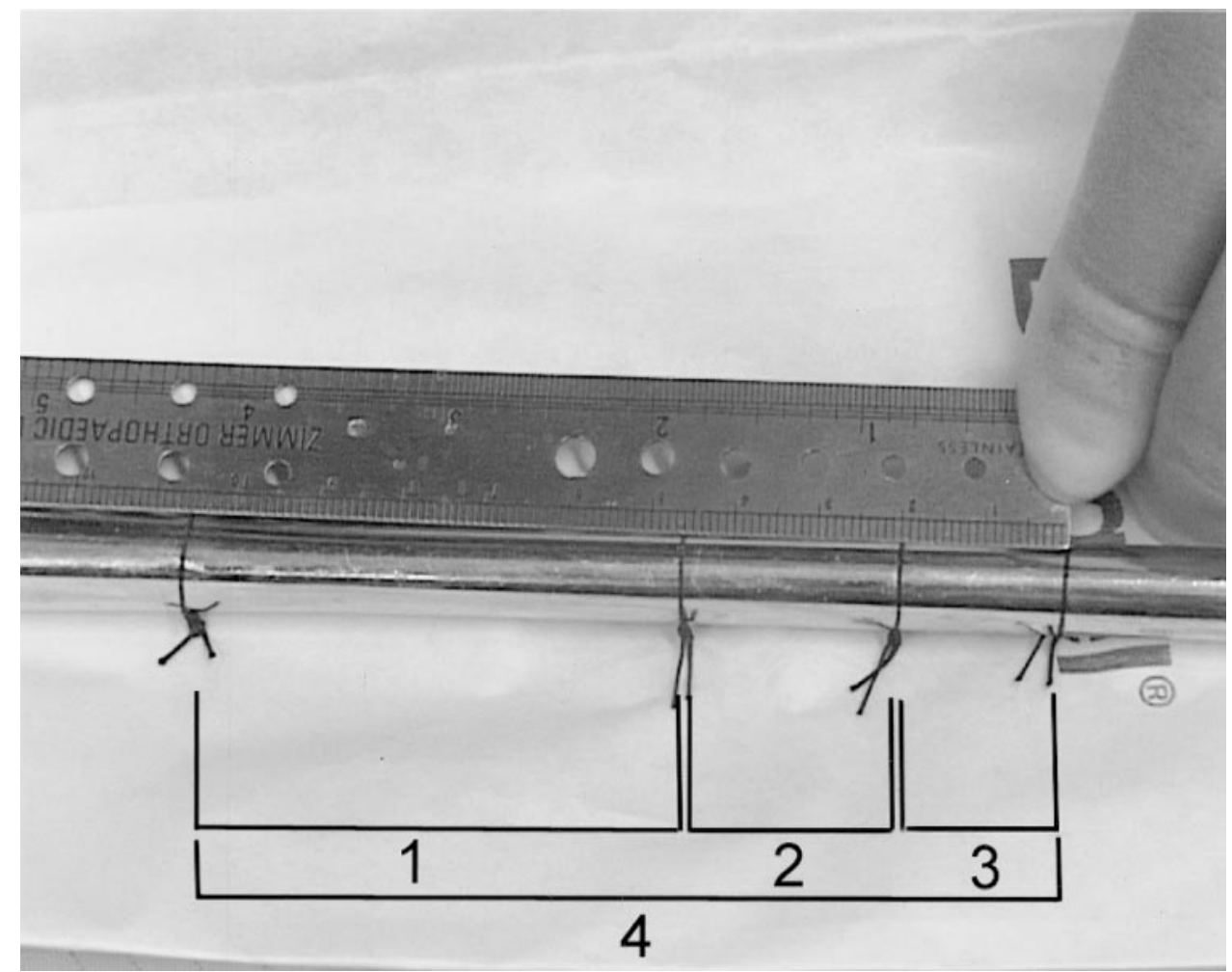

FIgURE 1. Measurements of tracheal stenosis made with a rigid bronchoscope: length of the normal trachea from the carina to the lower end of stenosis (1), length of tracheal stenosis (2), length of normal trachea from the superior level of stenosis to vocal cords (3), and total length of trachea (4).

Table 2-Comparison of Surgical Findings of Tracheal Stenosis Following PCT and SGT

\begin{tabular}{|c|c|c|c|}
\hline Variables & $\operatorname{PCT}(\mathrm{n}=15)$ & $\operatorname{SGT}(\mathrm{n}=14)$ & $\mathrm{p}$ Value \\
\hline Age (range), yr & $42(33-51)$ & $49(40-58)$ & 0.45 \\
\hline $\begin{array}{l}\text { Male/female gender, } \\
\text { No. }\end{array}$ & $8 / 7$ & $6 / 8$ & 0.72 \\
\hline $\begin{array}{l}\text { Mean weight }(95 \% \mathrm{CI}) \text {, } \\
\quad \mathrm{kg}\end{array}$ & $75.9(61.4-90.4)$ & $76.4(67.3-85.6)$ & 0.65 \\
\hline $\begin{array}{l}\text { Duration of mechanical } \\
\text { ventilation, } d^{*}\end{array}$ & $23.0(17.5-28.5)$ & $24(14-28)$ & 0.21 \\
\hline Onset of stenosis, wk* & $5.0(5.0-6.0) \uparrow$ & $28.5(12-84)$ & 0.009 \\
\hline $\begin{array}{l}\text { Mean distance below } \\
\text { vocal cords }(95 \% \\
\text { CI), cm }\end{array}$ & $1.6(1.1-2.1) \uparrow$ & $3.4(2.3-4.8)$ & 0.04 \\
\hline $\begin{array}{l}\text { Mean length of stenosis } \\
(95 \% \mathrm{CI}), \mathrm{cm}\end{array}$ & $2.8(2.4-3.3)$ & $2.7(2.2-3.1)$ & 0.39 \\
\hline $\begin{array}{l}\text { Mean diameter of } \\
\text { stenosis (95\% CI), } \\
\text { mm }\end{array}$ & $4.8(3.4-6.2)$ & $4.8(3.8-5.7)$ & 0.72 \\
\hline $\begin{array}{l}\text { Tracheoesophageal } \\
\text { fistula, No./total }\end{array}$ & $2 / 15$ & $0 / 14$ & 0.49 \\
\hline $\begin{array}{l}\text { Partial cricoid resection } \\
\text { and mucosal flap, } \\
\text { No./total }\end{array}$ & $7 / 15$ & $1 / 14$ & 0.23 \\
\hline
\end{tabular}

*Median (interquartile range).

$\uparrow \mathrm{p}<0.05$ compared to SGT group.
2.1) vs $3.4 \mathrm{~cm}$ (95\% CI, 2.3 to 4.8 ), respectively $(\mathrm{p}=0.04)$. Suprastomal cartilage damage (fracture or devoid) resulting in tracheal wall "caving-in" was a typical surgical finding in the PCT group, while marked (infra/supra) stomal granulations were frequently seen in the SGT group. A more complicated surgical technique (partial cricoid resection with mucosal flap) was more frequently used in PCT group ( 7 of 15 patients) than SGT ( 1 of 14 patients), although the difference did not reach the statistical significance $(p=0.23)$. We also found that the onset of tracheal stenosis after PCT was significantly shorter than that after SGT: 5.0 weeks (95\% CI, 5.0 to 6.0 ) vs 28.5 weeks (95\% CI, 12 to 84 weeks), respectively $(\mathrm{p}=0.009)$. However, we did not find a statistical significance between two groups in the length $(p=0.39)$ and in the diameter $(p=0.72)$ of stenosis.

This study, using rigid bronchoscopy for evaluating surgical findings of the tracheal stenosis, has demonstrated that tracheal stenosis caused by PCT requiring tracheal reconstruction was subglottic in nature. Our finding supports the findings of Dommerich et al, ${ }^{10}$ who reported endoscopic findings in 168 patients who underwent tracheostomy in situ for 10 days to 49 months in rehabilitation centers. They 


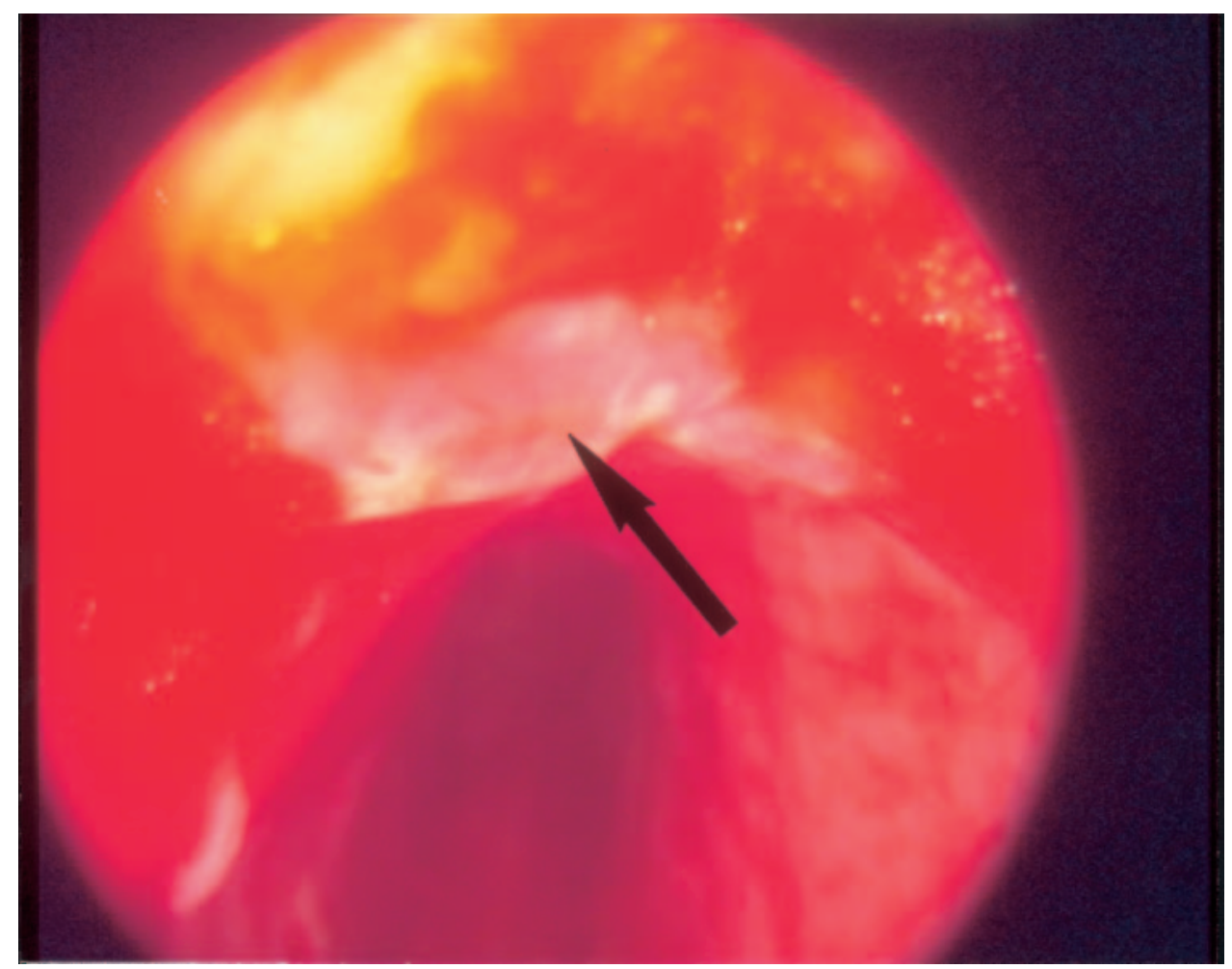

FIGURE 2. Fracture of tracheal cartilage following PCT. The cartilage can be seen protruding into the lumen of the trachea (arrow).

showed that the subglottic narrowing was present in $58 \%$ of PCTs compared with $17 \%$ of SGTs $(p<0.001)$. In our study, suprastomal cartilage damage resulting in tracheal wall caving-in was a typical surgical finding in the PCT group and absent in the SGT group. These findings were also consistent with results of Dommerich et $\mathrm{al},{ }^{10}$ in which approximately $4 \%$ vs $0 \%$ cartilage fractures in the subglottic area were found in PCT vs SGT groups, respectively. However, we found that marked stomal granulations were frequently seen in the SGT group, and there was no difference in the diameter of stenosis between two groups. In contrast, Dommerich et $\mathrm{a}^{10}$ demonstrated marked stomal granulations in both groups, and there was markedly increased narrowing of the trachea $(>50 \%)$ in the PCT group (25\% of patients) compared with the SGT group (0\% of patients). The more reliable method applied in our study, using rigid bronchoscopy with a dilator by a single operator, may have resulted in different outcomes compared to the study by Dommerich et al. ${ }^{10}$

A higher puncture site in the anterior tracheal wall can probably account for our observation that the PCT patients had a higher (subglottic) location than those in the SGT group. It is obvious that where the needle is inserted, either in the subglottic area or in the tracheal region, will determine where the stomal stenosis will develop. Interestingly, the reports of
Van Heurn et $\mathrm{al}^{11}$ and Dollner et $\mathrm{al}^{12}$ show that one third of the PCT punctures were blindly and wrongly inserted in the subglottic space. Therefore, if a stomal stenosis develops, it is more likely to be a subglottic stenosis. The needle should ideally pass between the second and third tracheal rings, although a space one higher or lower may be employed. Dulguerov et $\mathrm{al}^{13}$ and Ciaglia ${ }^{14}$ recommend not only using endoscopy ${ }^{13}$ but also using a video camera $^{14}$ to locate puncture sites between the second and third tracheal rings. Pretracheal soft-tissue dissection has also been recommended to provide better localization of the tracheal rings. ${ }^{11}$

Secondly, cartilage fractures may be also responsible for the subglottic stenosis following PCT. In the studies by Van Heurn et al ${ }^{11}$ and Dollner et al, ${ }^{12} 9$ of 19 severe tracheal stenoses were found to have tracheal or cricoid cartilage fractures. The characteristic feature of this kind of stenosis is caving-in of the tracheal wall by the fractures protruding into the tracheal lumen,11,12,15 and we observed the same findings in our study. The incidence of cartilage fracture following PCT has been reported as high as $87 \%$, and the majority of these fractures are located in the subglottic region. ${ }^{11,12}$ In contrast, the incidence of cartilage fracture caused by SGT were reported to be as low as $1.7 \% .^{16}$ 
In our study, subglottic stenosis was noted in 11 of 15 patients following PCT, and in 3 of 14 patients following SCT. The incorrect levels of needle puncture and caving-in of the tracheal cartilages might explain this difference predisposing to subglottic stenosis. It is, therefore, important to avoid oblique trachea puncture in order to reduce the incidence of cartilage fractures. By avoiding excessive force and too-large-sized tubes, we may be able to improve long-term outcomes following PCT. ${ }^{11}$

The most effective treatment for tracheal stenosis is tracheal resection and primary anastomosis. ${ }^{17,18}$ This technique ensures that patients return to their previous state of health. However, the surgery for tracheal stenosis in the subglottic region can be complex because of the presence of recurrent laryngeal nerve and the external branch of the superior laryngeal nerve in the subglottic area. ${ }^{19}$

In our study, we also found that the onset of tracheal stenosis after PCT was significantly shorter than that after SGT: 5.0 weeks (95\% CI, 5.0 to 6.0) vs 28.5 weeks (95\% CI, 12 to 84 weeks), respectively $(\mathrm{p}=0.009)$. This finding may be associated with the smaller diameter in the subglottic region, which would take a shorter period of time to develop clinical tracheal stenosis.

Suprastomal fracture resulting in caving-in of tracheal cartilages to narrow the tracheal lumen as seen in PCT compared with marked granulations resulting in stenosis as seen in SGT may also shorten the onset. The significant difference in onset of stenosis found in our study may have impacts on our clinical practice. Firstly, what is the ideal duration of follow-up to diagnose tracheal stenosis may depend on the type of tracheostomy. Currently, most authors ${ }^{4,20,21}$ use a minimum of 3 months for PCT follow-up, and this may be adequate; but this may well have underestimated the incidence of stenosis following SGT. ${ }^{18}$ The greater variations in the onset in SGT patients (range, 4 to 306 weeks) may be another factor of underestimating the true incidence of tracheal stenosis after SGT. Secondly, the shorter onset after PCT may make diagnosis followed by correct treatment more timely. In contrast, the prolonged onset after SGT may delay the treatment. In our study, patient 10 in the SGT group was treated for severe asthma for nearly 6 years and failed because the medical history of tracheostomy 6 years ago was completely forgotten in the differential diagnosis. This patient returned to her previous status of health after tracheal resection.

There are several limitations in this study. We attempted but failed to obtain the information on the different techniques in both the PCT and SGT groups because of difficulty in obtaining complete medical records. In addition, we attempted but also failed to obtain the information on duration of endotracheal intubation prior to tracheostomy. Prolonged endotracheal intubation prior to tracheostomy has been shown to be associated with posterior commissure injury caused by pressure of an endotracheal tube. ${ }^{22}$ However, our study excluded nonstomal stenosis, which would have excluded stenosis as results of prolonged intubation or cuff-induced stenosis. Furthermore, part of the study was retrospective. Few patients had to be excluded from the study due to information not being available. Also, details on the percentage reduction in transverse diameter of the trachea were not available in many of the radiologic reports.

In conclusion, in this observational study, we found that stenosis caused by PCT occurred earlier and was more subglottic in nature compared to that by SGT. Surgical correction of stenosis was more difficult in the PCT group due to its presentation in the subglottic area.

\section{REFERENCES}

1 Streitz JM, Shapshay SM. Airway injury after tracheotomy and endotracheal intubation. Surg Clin North Am 1991; 71:1211-1230

2 Finucane BT, Santora AH. Anatomy of the airway. In: Finucane BT, Santora AH, eds. Principles of airway management. 2nd ed. Boston, MA: Mosby, 1996; 1-18

3 Marx WH, Ciaglia P, Graniero KD. Some important details in the technique of percutaneous dilatational tracheostomy via the modified Seldinger technique. Chest 1996; 110:762-766

4 Van Heurn LWE, Goei R, de Ploeg I, et al. Late complications of percutaneous dilatational tracheostomy. Chest 1996; 110:1572-1576

5 Stauffer JL, Olson DE, Petty TL. Complications and consequences of endotracheal intubation and tracheostomy. Am J Med 1981; 70:65-76

6 Mansour KA, Lee RB, Miller JI. Tracheal resections: lessons learned. Ann Thorac Surg 1994; 57:1120-1125

7 Wood DE, Matheson DJ. Late complications of tracheotomy. Clin Chest Med 1991; 12:597-609

8 Courand L, Hafez A, Velly JF. Current reconstructive management of subglottic stenosis of the larynx. J Thorac Cardiovasc Surg 1985; 33:263-268

9 Grillo HC, Matheson DJ, Wain JC. Laryngo tracheal resection and reconstruction for subglottic stenosis. Ann Thorac Surg 1992; 53:54-59

10 Dommerich S, Graumúller S, Kramp B. Late sequelae of percutaneous tracheotomy compared to epithelized tracheostomy. Otolaryngol Pol 2001; 1:47-51

11 Van Heurn LWE, Theunissen PHMH, Ramsay G, et al. Pathological changes of the trachea after percutaneous dilatational tracheotomy. Chest 1996; 109:1466-1469

12 Dollner R, Verch M, Schweiger P, et al. Laryngotracheoscopic findings in long-term follow-up after Griggs tracheostomy. Chest 2002; 122:206-212

13 Dulguerov P, Gysin C, Perneger TV, et al. Percutaneous or surgical tracheostomy: a meta-analysis. Crit Care Med 1999; 27:1617-1625

14 Ciaglia P. Video-assisted endoscopy, not just endoscopy, for 
percutaneous dilatational tracheostomy. Chest 1999; 115: 915-916

15 Koitschev A, Graumueller S, Zenner HP, et al. Tracheal stenosis and obliteration above the tracheostoma after percutaneous dilational tracheostomy. Crit Care Med 2003; 31: 1574-1576

16 Achtzehn U, Budinger M, Weiss G, et al. Bronchoscopically controlled percutaneous puncture tracheotomy. Pneumologie 1998; 52:629-634

17 Fikkers BG, Briede IS, Verwiel JM, et al. Percutaneous tracheostomy with the Blue Rhino technique: presentation of 100 consecutive patients. Anaesthesia 2002; 57:1094-1097
18 Donahue DM. Reoperative tracheal surgery. Chest Surg Clin N Am 2003; 13:375-383

19 Grillo HC. Surgical treatment of postintubation tracheal injuries. J Thorac Cardiaovasc Surg 1979; 78:860-875

20 Mittendorf EA, McHenry CR, Smith CM, et al. Early and late outcome of bedside percutaneous tracheostomy in the intensive care unit. Am Surg 2002; 68:342-346

21 Hill BB, Zweng TN, Maley RH, et al. Percutaneous dilational tracheostomy: report of 356 cases. J Trauma 1996; 41:238243

22 Colice GL. Resolution of laryngeal injury following translaryngeal intubation. Am Rev Respir Dis 1992; 145:361-364 


\section{Is Tracheal Stenosis Caused by Percutaneous Tracheostomy Different From That by Surgical Tracheostomy? \\ Govindan Raghuraman, Sunil Rajan, Joseph Khalil Marzouk, Dam Mullhi and Fang G. Smith \\ Chest 2005; $127 ; 879-885$ \\ DOI 10.1378/chest.127.3.879}

This information is current as of February 24, 2007

\begin{tabular}{|c|c|}
\hline $\begin{array}{l}\text { Updated Information } \\
\text { \& Services }\end{array}$ & $\begin{array}{l}\text { Updated information and services, including } \\
\text { high-resolution figures, can be found at: } \\
\text { http://chestjournals.org/cgi/content/full/127/3/879 }\end{array}$ \\
\hline References & $\begin{array}{l}\text { This article cites } 18 \text { articles, } 7 \text { of which you can access } \\
\text { for free at: } \\
\text { http://chestjournals.org/cgi/content/full/127/3/879\#BIBL }\end{array}$ \\
\hline Permissions \& Licensing & $\begin{array}{l}\text { Information about reproducing this article in parts } \\
\text { (figures, tables) or in its entirety can be found online at: } \\
\text { http://chestjournals.org/misc/reprints.shtml }\end{array}$ \\
\hline Reprints & $\begin{array}{l}\text { Information about ordering reprints can be found online: } \\
\text { http://chestjournals.org/misc/reprints.shtml }\end{array}$ \\
\hline Email alerting service & $\begin{array}{l}\text { Receive free email alerts when new articles cite this } \\
\text { article sign up in the box at the top right corner of the } \\
\text { online article. }\end{array}$ \\
\hline Images in PowerPoint format & $\begin{array}{l}\text { Figures that appear in CHEST articles can be } \\
\text { downloaded for teaching purposes in PowerPoint slide } \\
\text { format. See any online article figure for directions. }\end{array}$ \\
\hline
\end{tabular}

A M E R I C A N C O L L E G E O F C H E S T $\begin{array}{llllllllll}\mathrm{P} & \mathrm{H} & \mathrm{Y} & \mathrm{S} & \mathrm{I} & \mathrm{C} & \mathrm{I} & \mathrm{A} & \mathrm{N} & \mathrm{S}\end{array}$ 